\title{
Estimation of Electron Current in Organic Light-Emitting Diodes Using an Operating Point Model
}

\author{
Tatsuo Mori*, Masato Imanishi**, Takao Nishikawa*** \\ *Department of Electrical Engineering, Aichi Institute of Technology, \\ 1247 Yachigusa, Yakusa-cho, Toyota, Aichi 470-0392, Japan \\ **Department of Electrical Engineering and Computer Science, \\ Nagoya University, Furo-cho, Chikusa, Nagoya, Aichi 464-8603, Japan \\ *** Center for Regional Collaboration in Research and Education, Iwate University \\ 4-3-5 Ueda, Morioka, Iwate, 020-8551, Japan \\ t2mori@aitech.ac.jp
}

\begin{abstract}
We propose the evaluation approach of the electron current in the bilayer organic light-emitting diode (OLED) using its device current and the hole current of hole transport material. The conduction current whose $50 \mathrm{~nm}$-thick diamine derivative ( $\alpha-\mathrm{NPD})$ layer is deposited on a fluorinated self-assembled monolayer (FSAM)-modified indium-tin-oxide (ITO), is presented by the space charge limited current (SCLC) mechanism. When the carrier balance factor is assumed to be a unity with the current continuity law, the electron current of the $\alpha-\mathrm{NPD} / \mathrm{aluminum}$ quinolone (Alq3) OLED can be evaluated experimentally. In addition, it is suggested that the electron current depends on the hole current from the comparison with the electron current of Alq3 single layer.
\end{abstract}

Keyword: organic light-emitting diode, SAM, operating point, electron current, hole injection

\section{Introduction}

In organic electronics fields, organic light-emitting diodes (OLEDs) [1] are used as the display of mobile phones, and as large 55-inch size TV display worldwide in 2014 and at Japan in 2015 by LG Electronics [2]. In the other functional field, organic photovoltaic cells [3-5], organic thin-film transistors [6-8], and organic thermoelectric devices $[9,10]$ are studied energetically. Organic devices are expected to contribute the next-generation electronic industrials.

Since organic materials are intrinsically insulating materials, there are small free carriers in organic materials. In order to apply an effective current to organic materials, carriers must be supplied by the injection from electrodes into the organic material. Previously since the research on the interface between organic and inorganic materials was not understood well, the electrical conduction of organic materials was analyzed by the Schottky injection model [11-13]. As the study on OLEDs is progressed, the electrode materials [14-16] and the interface doping techniques [17-19] for Ohmic injection have been developed.

We investigated the stability of film morphology [20], the carrier injection and device properties [21-27], and the formation of nano-dot [28] by preparation of fluorinated alkyl silole derivative on indium-tin-oxide (ITO). Especially it is important that the introduction of fluorinated self-assembled monolayer (FSAM) based on alkyl silole derivative improves the hole injection from ITO into a hole-transport material as a hole injection layer.

The conduction mechanism of a hole transport thin film $(\alpha-\mathrm{NPD})$ is perfectly regarded as the space charge-limited current (SCLC) using FSAM-modified ITO [24]. In this study, it is successful that the electron current flowing in 
OLED is evaluated considering the hole SCLC current and operating point of device. The part of this study was presented in Japan OLED Forum, $11^{\text {th }}$ Meeting, 2010 [29].

\section{Experimental}

\subsection{Materials and fabrication}

We describe $\mathrm{CF}_{3}\left(\mathrm{CF}_{2}\right)_{7}\left(\mathrm{CH}_{2}\right)_{2} \mathrm{Si}\left(\mathrm{OC}_{2} \mathrm{H}_{5}\right)_{3}$ as FSAM. We used $N, N^{\prime}$-di(1-naphthyl)- $N, N^{\prime}-$ diphenyl-1,1'-diphenyl-1,4'-diamine) ( $\alpha$-NPD) as a hole-transport material and 8-hydroxyquinoline aluminum (Alq3) as an emission material from Nippon Steel Chemical Co. in Fig.1. The substrates were cleaned by acetone, pure water and 2propanol with ultrasonic cleaning method. Finally they were cleaned by UV-ozone cleaning.

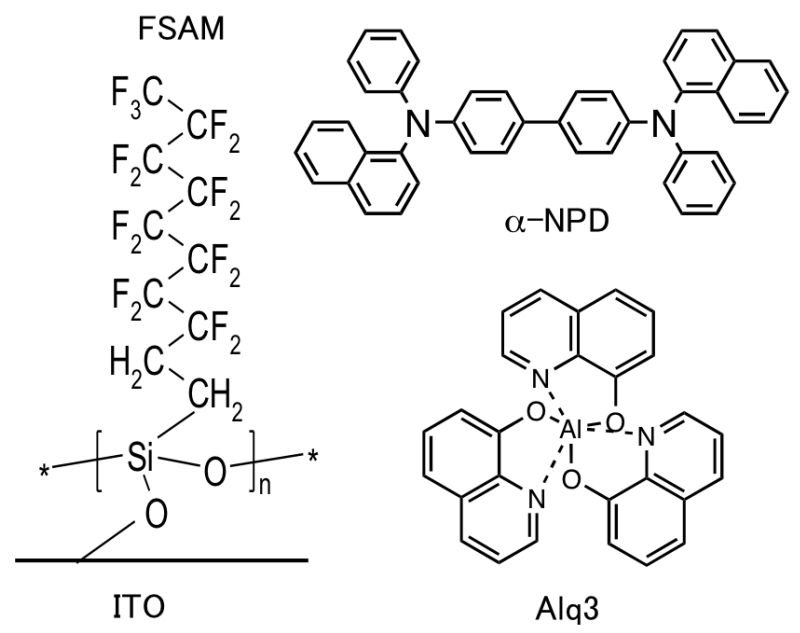

Figure 1. Chemical structures of materials.

Organic thin films were prepared on substrates. The organic thin films were prepared using the vacuum deposition at a pressure of $0.8 \sim 1 \times 10^{-3} \mathrm{~Pa}$ at room temperature. We carried out a vacuum-deposition with EO-55 (EIKO Co.).

\subsection{Measurements}

The work functions of ITO and organic materials are measured with the photoemission yield spectroscopy in air (AC-2, Riken Keiki Co.). Luminance-current-voltage characteristics were measured using a source measure unit (Keithley 2400 Source Measure Unit) and a luminance meter (TOPCON BM-8). The measurements of luminance-current-voltage characteristics were carried out under vacuum of $\sim 0.1 \mathrm{~Pa}$.

\section{Results and Discussion}

3.1. Analysis of hole current

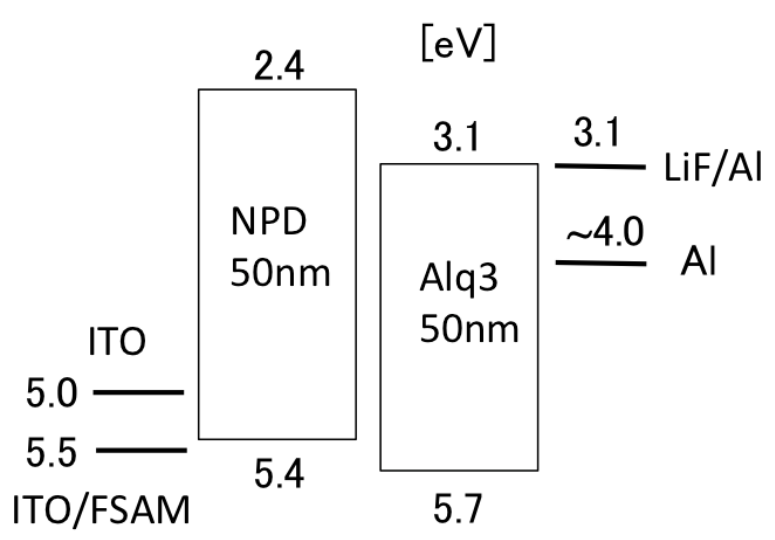

Figure 2. The energy diagram of $\alpha-\mathrm{NPD} / \mathrm{Alq} 3$ based OLED: These values present electron affinity and ionization energy of $\alpha$-NPD and Alq3, work functions of various electrodes.

Figure 2 shows the energy diagram of $\alpha-\mathrm{NPD} /$ Alq 3 based OLED. When the bare ITO and Al are used as an anode and a cathode respectively, the large barriers for the carrier injection exist in both two interfaces. On the other hand, when the ITO/ FSAM and $\mathrm{LiF} / \mathrm{Al}$ are used as an anode and a cathode respectively, there is no barrier in both two interfaces.

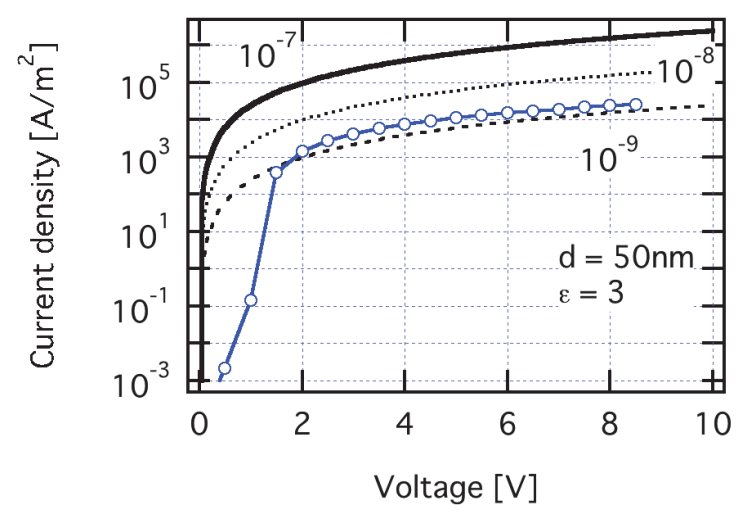

Figure 3. The current density - voltage curves of FSAM/ $\alpha$-NPD (50nm)/Al (open circles) and calculated SCLC (solid: hole mobility $\mu_{\mathrm{h}}=10^{-7}$, dot: $10^{-8}$, break: $\left.10^{-9} \mathrm{~m}^{2} / \mathrm{Vs}\right)$.

Figure 3 shows the current density - voltage characteristics of ITO/FSAM/ $\alpha-\mathrm{NPD}(50 \mathrm{~nm}) / \mathrm{Al}$ and SCLC currents calculated by hole mobilities of $10^{-7}, 10^{-8}$, and $10^{-9} \mathrm{~m}^{2} / \mathrm{Vs}$ when the dielectric constant of $\alpha$-NPD is assumed to be 3 . The equation of trap-free SCLC is obtained as the equation of (1) by Poisson's and Ohmic equations under the assumption of the uniformity of thin film and field-independent mobility. The current density, 


$$
J=\frac{9}{8} \varepsilon \mu \frac{V^{2}}{d^{3}}
$$

where $\varepsilon$ is the permittivity, $\mu$ is the carrier mobility, $V$ is applied voltage, and $d$ is thickness.

The hole mobility is estimated to be $1.37 \times 10^{-9}$ $\mathrm{m}^{2} / \mathrm{Vs}$ from the experimental curve. Since the hole mobility of $\alpha$-NPD is estimated to be $10^{-8} \mathrm{~m}^{2} / \mathrm{Vs}$ order by means of time-of-flight (TOF) method [30], it is 1-order higher than the hole mobility obtained from SCLC model. If we use the hole mobility obtained from TOF method, we must modify the equation (1) and need use the following shallow trap SCLC model.

$$
J=\frac{9}{8} \Theta \varepsilon \mu \frac{V^{2}}{d^{3}}
$$

where $\Theta$ is a coefficient and the ratio of trap carrier density to free carrier density. The equation (2) is described as the product of the equation (1) and the coefficient of $\Theta$. In this case, $\Theta$ is regarded as almost $1 / 10$, which corresponds to the ratio of SCLC and TOF hole mobilities.

\subsection{Analysis of current behavior in bilayer OLED} due to hole current in a single layer
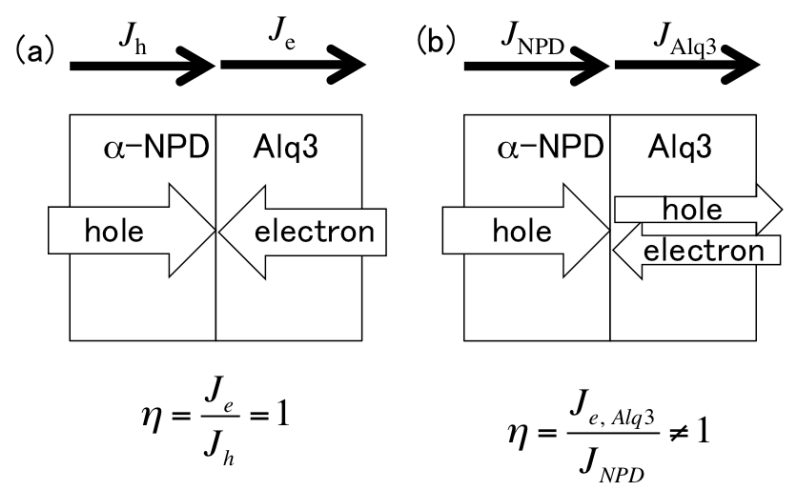

Figure 4. The carrier flows (white arrows) and currents (black arrows) image of (a) good and (b) poor carrier balance conditions. $\eta$ is the carrier balance factor.

Figure 4 presents the good and poor carrier balance conditions. $J$ means current density. The $J_{\mathrm{h}}$ and $J_{\mathrm{e}}, J_{\mathrm{NPD}}$ and $J_{\mathrm{Alq} 3}$ mean hole and electron currents, and the currents flowing in $\alpha-\mathrm{NPD}$ and Alq3 layers, respectively. White arrows are described as hole and electron flows. In Fig. 4(a), $J_{\mathrm{h}}$ and $J_{\mathrm{e}}$ are equal to $J_{\mathrm{NPD}}$ and $J_{\mathrm{Alq} 3}$. In this case, the carrier balance factor is a unity. In Fig. 4(b), however, although $J_{\mathrm{NPD}}$ is equal to $J_{\mathrm{h}}, J_{\mathrm{Alq} 3}$ is not equal to $J_{\mathrm{e}}$ because of leak hole current. The carrier balance factor is less than 1 . Our following method cannot be applied to the OLED with a poor carrier balance factor.

When the hole current density from $\alpha$-NPD is surely recombined with the electron current density in Alq3 in the $\alpha$-NPD/Alq3 bilayer OLEDs, the carrier balance factor is a unit. If the carrier balance factor is a unit as shown in Fig. 4(a), the behavior of electron current in OLEDs depends on the conduction of hole current. In addition, when the carrier injection is Ohmic and the carrier ejection into organic layer is the same as that into an electrode, the current behavior in each organic layer against a divided voltage in multi-layer OLED is thought to be the same as that in a single layer.

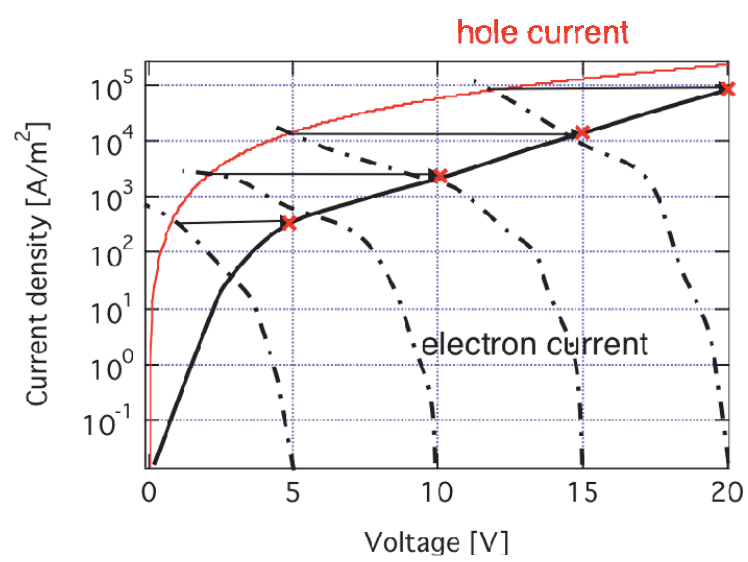

Figure 5. The concept image for the estimation of $\mathrm{J}-\mathrm{V}$ curve of $\alpha$-NPD/Alq3 bilayer device from the operating point between hole and electron currents.

As shown in Fig. 5, when the hole current is controlled by the SCLC mechanism and an arbitrary current density - voltage curve of an electron current is known (the electron current may not be always controlled by the SCLC mechanism), the driving voltage of the device at an applied voltage is determined by the operating point, i.e., the intersection of the hole current and electron current curves. For example, when the applied voltage to the device is $5 \mathrm{~V}$, one draws the electron current curve from $5 \mathrm{~V}$ as the starting point. One can obtain the intersection between hole and electron currents. The current at the intersection is $\mathrm{J}_{5 \mathrm{v}}$, the current flowing into the device at the applied voltage of $5 \mathrm{~V}$. In the same manner, if the operating points between the hole and electron currents are calculated at $10,15,20 \mathrm{~V}$, etc., the current density - voltage characteristics of the device can be obtained. This curve is described as the hole current curve pushed aside to the higher 
voltage. The current curve that we can obtain most easily in experiment is the current curve of the device and the hole current curve is obtained secondly easily.

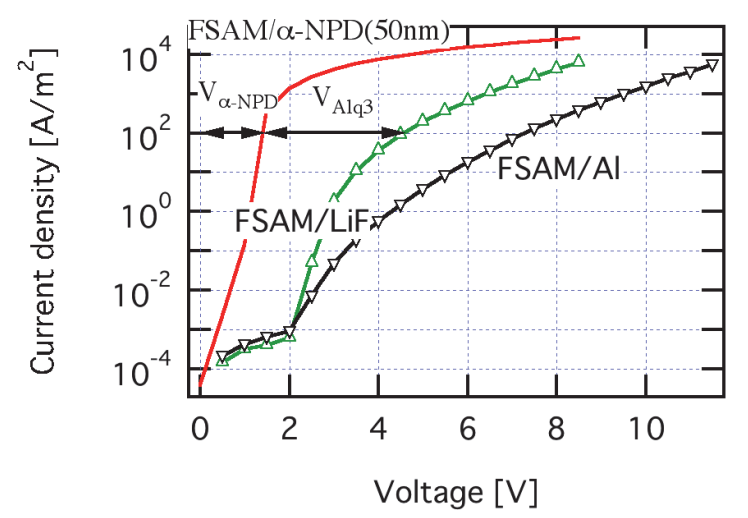

Figure 6. The current density - voltage characteristics of ITO/FSAM/ $\alpha-N P D(50 \mathrm{~nm}) / \mathrm{Al}$ (line), ITO/FSAM/ $\alpha-\mathrm{NPD}(50 \mathrm{~nm}) / \mathrm{Alq} 3(50 \mathrm{~nm}) / \mathrm{LiF} / \mathrm{Al}$ (triangles), and ITO/FSAM $/ \alpha-N P D \quad(50 \mathrm{~nm}) / \mathrm{Alq} 3(50 \mathrm{~nm}) / \mathrm{Al}$ (inverse triangles). $V_{\alpha \text {-NPD }}$ and $V_{\text {Alq3 }}$ show the divided voltage of $\alpha$-NPD and Alq3 layers at $10^{-2} \mathrm{~A} / \mathrm{m}^{2}$.

Therefore, we estimate the electron current from the device and hole currents' behaviors. Figure 6 shows the current density voltage characteristics of ITO/FSAM $/ \alpha-$ $\mathrm{NPD}(50 \mathrm{~nm}) / \mathrm{Al}, \quad$ ITO/FSAM $/ \alpha-\mathrm{NPD}(50 \mathrm{~nm}) /$ $\mathrm{Alq} 3(50 \mathrm{~nm}) / \mathrm{LiF} / \mathrm{Al}$, and ITO/ $\mathrm{FSAM} / \alpha-$ $\mathrm{NPD}(50 \mathrm{~nm}) / \mathrm{Alq} 3(50 \mathrm{~nm}) / \mathrm{Al}$. If only the hole current increases, the carrier balance factor is not often a unity. Consequently, the EL efficiency (luminance per current density) will reduce. In Alq3-based bilayer OLED with LiF/Al cathode, however, although the introduction of FSAM as a hole injection layer enhances the hole injection, the EL efficiency per current density shows the same behavior in spite of the increase in hole injection [24]. This suggests the electron injection from $\mathrm{LiF} / \mathrm{Al}$ and the electron transport in Alq3 layer keep pace with supplying holes to recombination zone. As shown in Fig. 5, the J-V curve of the specimen without LiF electron injection layer agrees with that of the specimen with $\mathrm{LiF}$ electron injection layer expanded to the higher voltage region. Since the divided voltage of $\alpha$-NPD layer is estimated from the J-V curve of $\alpha-N P D$ single layer, the divided voltage of Alq3 layer is described as the voltage difference between device and $\alpha$-NPD single layer voltages under a same constant current. When one repeats the above procedure at many current densities, one can obtain many current density - voltage pairs of electron current density in the device.

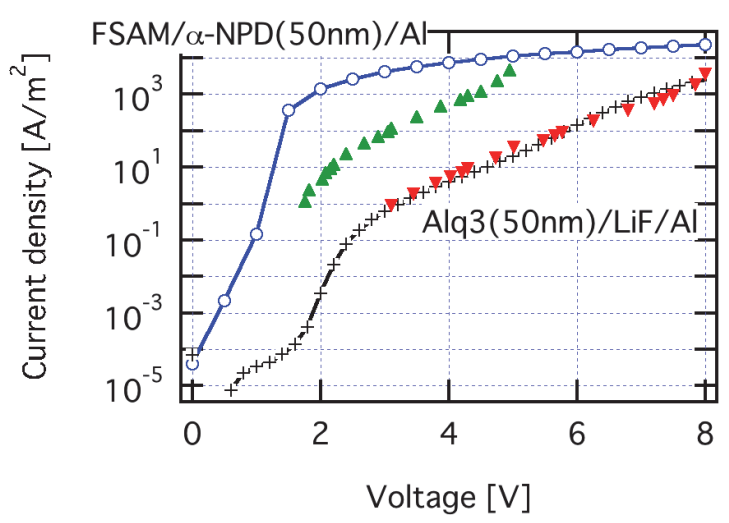

Figure 7. The current density - voltage characteristics of hole current ITO/FSAM/ $\alpha$-NPD (50nm)/Al (circles), and electron current densities of ITO/FSAM/ $\alpha-\mathrm{NPD}(50 \mathrm{~nm}) / \mathrm{Alq} 3(50 \mathrm{~nm}) / \mathrm{LiF} / \mathrm{Al}$ (triangle s) and ITO/FSAM/ $/ \alpha-N P D(50 \mathrm{~nm}) / \mathrm{Alq} 3(50 \mathrm{~nm}) \quad / \mathrm{Al}$ (inverse triangles).

Figure 7 shows the current density - voltage characteristics of ITO/FSAM/ $\alpha-\mathrm{NPD}(50 \mathrm{~nm}) / \mathrm{Al}$ (circles) and ITO/Alq3(50nm)/LiF/Al (crosses), and two estimated electron current density voltage curves. Green triangles and red inverse triangles are described as each electron current density of ITO/FSAM/ $\alpha-\mathrm{NPD}(50 \mathrm{~nm}) / \mathrm{Alq} 3(50 \mathrm{~nm}) /$ $\mathrm{LiF} / \mathrm{Al}$, and ITO/FSAM/ $\alpha-\mathrm{NPD}(50 \mathrm{~nm}) / \mathrm{Alq} 3$ $(50 \mathrm{~nm}) / \mathrm{Al}$, respectively. The current of ITO/ $\mathrm{Alq} 3(50 \mathrm{~nm}) / \mathrm{LiF} / \mathrm{Al}$ is almost regarded as an electron current because of higher barrier height of hole injection at the ITO/Alq3 interface. This current curve agrees with the electron current curve of ITO/FSAM/ $\alpha-\mathrm{NPD}(50 \mathrm{~nm}) / \operatorname{Alq} 3(50 \mathrm{~nm}) /$ Al. Since the electron injection condition is same, the electron current curve of ITO/FSAM $/ \alpha$ $\mathrm{NPD}(50 \mathrm{~nm}) / \mathrm{Alq} 3(50 \mathrm{~nm}) / \mathrm{LiF} / \mathrm{Al}$ was expected to agree with that of ITO/FSAM/ $\alpha-N P D(50 \mathrm{~nm}) /$ Alq3 $(50 \mathrm{~nm}) / \mathrm{Al}$. However the electron current curve of ITO/FSAM/ $\alpha-\mathrm{NPD}(50 \mathrm{~nm}) / \mathrm{Alq} 3(50 \mathrm{~nm}) /$ $\mathrm{LiF} / \mathrm{Al}$ is 2-orders higher than that of ITO/FSAM/ $\alpha-\mathrm{NPD}(50 \mathrm{~nm}) / \mathrm{Alq} 3(50 \mathrm{~nm}) / \mathrm{Al}$. This suggests the increase of hole current enhances the electron injection from $\mathrm{LiF} / \mathrm{Al}$ into Alq3 layer. In addition, this result means that the EL efficiency per current density is almost constant against the increase in hole injection.

As above, if the carrier balance of the device is a unity, it is found that the electron current density voltage characteristics in the device can be estimated from our procedure.

\subsection{Influence of built-in potential}

As shown in Fig. 2, since the specimens of 
ITO/FSAM/ $\alpha-\mathrm{NPD} / \mathrm{Al}$ and ITO/Alq3/LiF/Al are existed by hetero electrodes, a built-in potential occurs in the specimen. The built-in potentials in the former and the latter are $1.5 \mathrm{~V}$ and $2 \mathrm{~V}$, respectively. The direction of electric field of both built-in potentials are the inverse to the carrier injection, Therefore, even if the carrier injection at the ITO/FSAM/ $\alpha$-NPD interface is Ohmic, it is thought that the carrier transport is inhibited until the external electric field is over the built-in potential. On the other hand, the built-in potential of $2.4 \quad \mathrm{~V}$ occurs in the ITO/FSAM/ $\alpha-N P D / A l q 3 / \mathrm{LiF} / \mathrm{Al}$. In this specimen, the resistance of Alq3 emission layer is thought to be $>1$ order higher than that of $\alpha-\mathrm{NPD}$ hole-transport layer because the hole mobility of $\alpha-N P D$ is 2 orders higher than the electron mobility of Alq3 [31]. The shared voltage of total built-in potential in the bilayer specimen, of $\alpha$-NPD layer is thought to be smaller than the built-in potential in ITO/FSAM/ $\alpha-\mathrm{NPD} / \mathrm{Al}$. It is possible that the shared voltage due to electron current $\left(V_{\mathrm{Alq}}\right)$ is regarded as smaller estimation in Fig. 6. If so, the difference of electron current between the experimental and calculated values may be explained by considering the built-in potential.

If the built-in potential is considered in SCLC model, the equation (1) can be modified as the equation (3),

$$
J=\frac{9}{8} \varepsilon \mu \frac{\left(V-V_{b}\right)^{2}}{d^{3}}
$$

where $V_{\mathrm{b}}$ is a built-in potential. The voltage shift of initial current rise of ITO/FSAM/ $\alpha-\mathrm{NPD} / \mathrm{Al}$ may be explained by the built-in potential. However, the current density of ITO/FSAM/ $\alpha-\mathrm{NPD} / \mathrm{Al}$ is proportional to the square applied voltage, $V_{2}$ but not $\left(V-V_{\mathrm{b}}\right)^{2}$. Figure 8 shows the current curves calculated due to the equation (3) with the experimental curve. The current curve simply calculated by the equation (3) and carrier mobility of $1.37 \times 10^{-9} \mathrm{~m}^{2} / \mathrm{Vs}$ with the built-in potential, 1.5 $\mathrm{V}$ is the red solid line increasing from $1.5 \mathrm{~V}$. The red dotted line increasing from $1.5 \mathrm{~V}$ is the current changed with the higher carrier mobility of $5 \times 10^{-9}$ $\mathrm{m}^{2} / \mathrm{Vs}$ because of smaller current values of red solid line. The current curve increasing from $1 \mathrm{~V}$ or $1.2 \mathrm{~V}$ is calculated as the carrier mobility of $5 \times 10^{-9}$ $\mathrm{m}^{2} / \mathrm{Vs}$ or $6 \times 10^{-9} \mathrm{~m}^{2} / \mathrm{Vs}$, respectively.

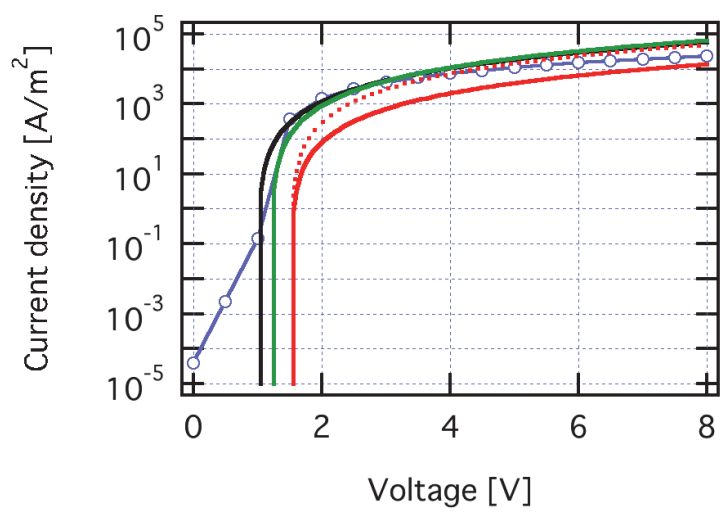

Figure 8. The current curves calculated due to the equation (3) with the experimental curve of ITO/FSAM/ $\alpha-N P D(50 \mathrm{~nm}) / \mathrm{Al}$ (circles).

But all calculated curves do not agree with the experimental one. Some researchers simulated the conduction of $\alpha$-NPD thin film using the SCLC modified with electric-field-dependent Pool-Frenkel type mobility [32-34]. However, all calculated curves obviously show some different electric-field-dependence from the experimental curve. The Pool-Frenkel type mobility is described as

$$
\mu=\mu_{0} \exp (\gamma \sqrt{E})
$$

where $\mu_{0}$ is a constant mobility, $E$ is an electric field, and $\gamma$ is a Pool-Frenkel factor. Therefore, when the Pool-Frenkel mobility is used to the simulation, the electric field-dependence will be emphasized at the higher voltage region. We will discuss the influence of built-in potential by experiments and simulation in future.

\section{Conclusion}

In a typical $\alpha$-NPD/Alq3 bilayer OLED, We evaluated the $J-V$ curve of electron current in OLEDs by the difference between the J-V curve of device and the J-V curve (hole current) of hole transport single layer with Ohmic contact. This electron current agreed with the electron-dominant current of Alq3 single layer qualitatively. By the quantitative comparison of OLEDs with or without $\mathrm{LiF}$ electron injection layer, the increase in hole injection was found to enhance the electron injection from the cathode.

\section{Acknowledgements}

This research is partially obtained by a financial assistance of a MEXT-Supported Program for the 
Strategic Research Foundation at Private Universities (S1001033, 2010-2014) and the AIT Special Grant for Education and Research, the AIT Special Grant "Development of Hybrid-Power Science \& Technology for Green-Energy", and JSPS Grant-in-Aid for Scientific Research (C) 15K060410001

\section{References}

1. C. W. Tang and S. A. VanSlyke: Appl. Phys. Lett., 51 (1987) 913.

2. http://www.lg.com/us/experience-tvs/oled-tv.

3. C. Sekine, Y. Tsubata, T. Yamada, M. Kitano and S. Doi, Sci. Technol. Adv. Mater., 15 (2014) 034203.

4. C. Deibel and V. Dyakonov, Rep. Prog. Phys. 73 (2010) 096401.

5. K. A. Mazzio and C. K. Luscombe, Chem. Soc. Rev., 44 (2015) 78.

6. Y. Wakayama, R. Hayakawa and H.-S. Seo, Sci. Technol. Adv. Mater., 15 (2014) 024202.

7. D. Choi, P.-H. Chu, M. McBride and E. Reichmanis, Chem. Mater., 27 (2015) 4167.

8. D. Martin Taylor, Jpn. J. Appl. Phys., 55 (2016) 02BA01.

9. O. Bubnova, Z. U. Khan, A. Malti, S. Braun, M. Fahlman, M. Berggren and X. Crispin, Nat., Mater, 10 (2011) 429.

10. Q. Wei, M. Mukaida, K. Kirihara, Y. Naitoh and T. Ishida, RSC Adv., 4 (2014) 28802.

11. J G Simmons, J. Phys. D, 4 (1971) 613.

12. S.R. Forrest, M.L. Kaplan and P.H. Schmidt, $J$. Appl. Phys., 55 (1984) 1492.

13. I. H. Campbell and D. L. Smith, Appl. Phys. Lett., 74 (1999) 561.

14. J. Kido, C. Ohtani, K. Hongawa, K. Okuyama and K. Nagai, Jpn. J. Appl. Phys. 32 (1993) L917.

15. L. S. Hung, C. W. Tang and M. G. Mason, Appl. Phys. Lett., 70 (1997) 152.

16. S. Tokito, K. Noda and Y. Taga, J. Phys. D, 29 (1996) 2750.
17. J. Endo, T. Matsumoto and J. Kido, Jpn. J. Appl. Phys., 41 (2002) L800.

18. G. He, M. Pfeiffer, K. Leo, M. Hofmann, J. Birnstock, R. Pudzich and J. Salbeck, Appl. Phys. Lett., 85, (2004) 3911.

19. Y. Li, D.-Q. Zhang, L. Duan, R Zhang, L. D. Wang and Y. Oui. Appl. Phys. Lett., 90 (2007) 012119.

20. T. Mori, S. Nishino, T. Nishikawa and S. Ogawa, Organic Electronics, 9 (2008) 63.

21. T. Mori, S. Nishino, T. Nishikawa and $\mathrm{S}$. Ogawa, Jpn. J. Appl. Phys., 47 (2008) 455.

22. T. Mori, M. Imanishi and T. Nishikawa, Appl. Phys. Exp., 4 (2011) 071601.

23. T. Satoh, M. Imanishi, T. Nishikawa and $\mathrm{T}$. Mori, Jpn. J. Appl. Phys., 51 (2012) 035701.

24. T. Mori, M. Imanishi and T. Nishikawa, $J$. Photopolym. Sci. Technol., 25 (2012) 327.

25. T. Mori, X. Ma, H. Furuhashi and T. Nishikawa, J. Photopolym. Sci. Technol., 26 (2013) 377.

26. T. Mori, K. Imai, H. Furuhashi and T. Nishikawa, J. Photopolym. Sci. Technol., 27 (2014) 327.

27. S.-G. Park and T. Mori, Luminescence, 30 (2015) 416.

28. T. Mori, T. Morimoto and T. Nishikawa, Appl. Phys. Express, 4 (2011) 111601.

29. T. Mori, M. Imanishi and T. Nishikawa, Japan OLED Forum, $11^{\text {th }}$ Meeting, (2010) S3-3 [in Japanese].

30. T. Mori, E. Sugimura, T. Kichimi and T. Mizutani, J. Phys. D, 25 (1992) 1817.

31. S. Naka, H. Okada, H. Onnagawa, Y.Yamaguchi, T. Tsutsui, Synthetic Metals, 111-112 (2000) 331

32. R. D. Gould, Thin Solid Films, 125 (1985) 63.

33. J. Staudigel, M. Stößel, F. Steuber and J. Simmerer, Appl. Phys., 86 (1999) 3895.

34. Y. Hu and H.-B. Rao, Chin. Phys. B, 18 (2009) 1627. 